\title{
International Management as Management of Diversity: Reconceptualizing Distance as Diversity
}

\section{Fabrice Lumineau ${ }^{a}$, Marvin Hanisch $^{\mathrm{b}}$ and Olivier Wurtz}

${ }^{a}$ Purdue University; ${ }^{b}$ University of Groningen; ${ }^{c}$ University of Vaasa

ABSTRACT Despite the importance of distance in international business and management research, the theoretical foundation for the concept and the underlying causal mechanisms are subject to shortcomings. We propose reinvigorating the study of distance through a diversity lens. We draw on research on diversity and develop a theoretical framework that distinguishes types of diversity (separation, variety, and disparity) at three levels (institutional, organizational, and individual). We show how this framework allows scholars to extend their analysis of distance, revisit important questions, and explore new issues. We discuss the theoretical and empirical implications of our diversity lens for the international business and management community.

Keywords: conceptual framework, distance, diversity, international business, international management

\section{INTRODUGTION}

The notion of distance - broadly defined as 'the difference between two things' (Oxford University Press, 2020) - is at the heart of International Business/International Management (hereafter IB/IM) research (Beugelsdijk et al., 2018a). A recent review listed more than 300 published articles on distance during the last three decades (Verbeke et al., 2018b). Despite the significant advances in our understanding of cross-national differences and foreignness (e.g., Kirkman et al., 2006, 2017), this field of research has paid relatively little attention to the conceptualization of distance (e.g., Ambos and Håkanson, 2014; Shenkar et al., 2008). In particular, distance has been mostly perceived as a liability involving costs and negative outcomes (Beugelsdijk et al., 2018b; Zaheer, 1995). Although some studies have begun to propose potential advantages of foreignness (e.g., Edman,

Address for reprints: Marvin Hanisch, University of Groningen, Nettelbosje 2, 9747 AE Groningen, The Netherlands (m.hanisch@rug.nl).

This is an open access article under the terms of the Creative Commons Attribution-NonCommercialNoDerivs License, which permits use and distribution in any medium, provided the original work is properly cited, the use is non-commercial and no modifications or adaptations are made. 
2016; Shenkar, 2001; Stahl et al., 2016), we still do not have a clear understanding of the underlying mechanisms by which distance creates liabilities or advantages. Accordingly, recent calls have suggested scholars should "unpack the black box we call "distance" by exploring the micro-level mechanisms involved' (Dow, 2018, p. 53; Edman, 2016; Zaheer et al., 2012).

Prior research has rarely explored the mechanisms underlying the construct of distance. We argue that this disregard is attributable to insufficient consideration of the distinct types of distance and the levels at which they are studied. In this article, we show why an undifferentiated study of distance masks substantive distinctions about its influence. We suggest that important opportunities are overlooked because of the manner in which distance has traditionally been conceptualized in the IB/IM literature. First, we provide an overview of the literature on distance in IB/IM and highlight some assumptions and subsequent limitations. Second, we advance an alternative way to study the issues arising from the distance between entities. Specifically, we draw on research on diversity to introduce the distinction among separation, variety, and disparity (e.g., Bunderson and Sutcliffe, 2002; Harrison and Klein, 2007) to IB/IM research. Third, we discuss how a diversity framework at the institutional, organizational, and individual levels could allow scholars to extend their analysis of distance, revisit important questions, and explore new issues. We specifically draw attention to opportunities regarding, for instance, the management of expatriates, headquarters-subsidiary relationships, and international entry modes. Fourth, we discuss the theoretical and managerial implications of our diversity lens.

Our study departs from and extends the current literature on distance in two major ways. First, our theoretical contribution aims at disentangling coexisting and sometimes conflicting effects underlying distance. In particular, we advance a parsimonious conceptual framework inspired by the diversity literature that offers a richer and more nuanced terminology, which allows us to specify distinct mechanisms that are conflated under the broad term of distance. Thus, our diversity lens helps us understand the intrinsic ambivalence of distance and reconcile the debates over the influence of distance. In this manner, we tackle the longstanding lack of theorization on distance (Dow, 2018; Maseland et al., 2018). Second, while understanding that the influence of distance at the institutional level is central to IB/IM research with its interest in cross-national differences, we emphasize that relevant sources of diversity for many IB/IM topics originate not only at the institutional level but also at the individual and organizational level. Thus, we suggest that the study of diversity benefits from a multi-level approach. In sum, we broaden the prevailing conceptualization of distance through a diversity lens and distinguish among diversity originating at the institutional, organizational, and individual levels.

\section{DISTANGE IN INTERNATIONAL BUSINESS AND MANAGEMENT}

Distance is one of the most widely studied concepts in IB/IM research (Verbeke et al., 2018a). Thus, it is not without justification that Zaheer et al. (2012, p. 19) argue that 'international management is management of distance'. Recent reviews have noted the proliferation of research on different types of distance, including cultural, linguistic, regulatory, administrative, political, institutional, geographic, and economic differences 
between entities (Ambos and Håkanson, 2014; Hutzschenreuter et al., 2016). Overall, IB/IM scholars have mostly provided 'extensional' definitions of distance that focus on the constituent parts of distance (i.e., by listing all the different forms of distance) rather than offering a definition that attempts to describe the essential properties of distance. Consequently, the literature on distance remains largely fragmented and lacks a parsimonious analytical framework with which to understand the mechanisms underlying the influence of distance.

In recent years, scholars have increasingly challenged the concept of distance (Berry et al., 2010; Shenkar, 2012; Stahl et al., 2016; Tung and Verbeke, 2010; Zaheer et al., 2012). Some of this criticism is based on the simplified conceptualization of distance that is analogous to geographical distance (e.g., Kogut and Singh, 1988). This concern is summarized by Ambos and Håkanson (2014, p. 4):

Despite the devastating critique of the conventional [use] of distance in mainstream international business journals and repeated calls for theoretical advances (Berry et al., 2010; Håkanson and Ambos, 2010; Shenkar, 2001, 2012; Tihanyi et al., 2005; Zaheer et al., 2012), a surprisingly small number of empirical and conceptual studies have taken up the challenge to develop new and theoretically sounder conceptualizations.

Thus, contemporary distance research needs to shift 'from exploring whether distance matters' to understanding 'why and how it matters' (Dow, 2018, p. 55). A case in point is the dominant assumption in the IB/IM literature that distance implies detrimental consequences. For instance, distance is usually assumed to be a barrier to the transfer of information, thus increasing the uncertainty and ambiguity that actors face (Hofstede, 2001; Johanson and Vahlne, 1977). As a result, it has often been argued that greater distance creates additional costs and liabilities for firms operating in foreign markets (Dikova and Rao Sahib, 2013; Johanson and Vahlne, 2009). Some research has challenged this traditional assumption of distance as a liability, choosing to also consider the potential benefits of distance (Edman, 2016; Stahl et al., 2016). In particular, Stahl et al. (2017) encourage scholars to consider the 'upside' of distance instead of stigmatizing distance as a problem, and Stahl and Tung (2015, pp. 406-07) call to provide a better understanding of 'differences and distance used in the field of IB'. Whereas some recent studies have started to highlight the negative and positive sides of distance (Joardar and Wu, 2017; Pesch and Bouncken, 2017) or considered the contingent effect of distance that hinges on contextual variables (Stahl and Tung, 2015), the underlying conceptualization of distance has not changed with these studies, which makes it difficult to understand exactly why distance can lead to positive or negative outcomes. To overcome this apparent conundrum, we argue that we need a more nuanced theoretical foundation of distance that captures the inherent complexity of the construct and enables scholars to revisit and better understand relevant phenomena in IB/IM research.

Although scholars are likely to be aware of the specific meaning of distance in their individual research, when considering the issue at the discipline level, we find it problematic to use a single (umbrella) term to represent very different realities and mechanisms. Thus, we express concerns about the fact that the overarching 'distance' construct remains too general, if not convoluted, and that many authors in IB/IM may implicitly 
assume that the reader understands the intended meaning. In bringing greater clarity to the diverse meanings of distance, we hope to provide the research community with a common language that is 'an essential prerequisite for a community of scholars interested in the same or similar phenomena to exchange ideas and build knowledge' (Suddaby, 2010, p. 352). Sharpening the meaning of distance and elucidating its diverse and conceptually distinct forms can help us understand where ideas overlap and when they diverge, and more accurately articulate relationships between constructs and their underlying mechanisms. Such clarity can advance our ability to theorize on and predict empirical phenomena. Therefore, we believe that our essay helps provide such clarity of which scholars may have been implicitly aware but failed to make explicit.

\section{LEVERAGING THE LITERATURE ON DIVERSITY}

Scholarly contributions on distance and diversity have largely developed independently as distinct fields of research. This situation is surprising given the conceptual overlap and proximity of the problems that these streams of research address. It is worthwhile to note that the definitions of both distance (Shenkar, 2012) and diversity (Harrison and Klein, 2007) refer to understanding differences across entities. For instance, Beugelsdijk et al. (2018b, p. 90) define distance as 'difference between countries' in the IB/IM context, whereas van Knippenberg et al. (2004, p. 1008) define diversity as 'differences between individuals' in the work group context, which illustrates the similarity of the two concepts, albeit at different levels. Based on this similarity, we thus propose leveraging the literature on diversity to develop a richer and theoretically more nuanced framework for research on distance in IB/IM.

A large body of research has emphasized the importance of understanding the diversity of partners involved in collective action (see Nishii et al., 2018; Roberson et al., 2017; Srikanth et al., 2016, for recent reviews of the field). Early studies tied diversity to some form of difference but rarely substantiated the nature of those differences (Bunderson and Sutcliffe, 2002). However, as Harrison and Klein (2007) note, disentangling the different facets of diversity unmasks substantive distinctions. Based on an extensive review of the literature, Harrison and Klein (2007) identified three clearly discernible but sufficiently exhaustive types of diversity. First, separation refers to differences in positions or opinions among unit members and, thus, represents dissimilarity in a particular attitude or value. Second, variety denotes differences in types or categories, primarily of information, knowledge, or experience among unit members. Finally, disparity refers to differences in the concentration of valued social assets or resources among unit members. Recent studies have built on this framework and have elaborated on the mechanisms of diversity and shown how these different facets of diversity affect organizational performance differently (Bell et al., 2011; van Dijk et al., 2017; Roberson et al., 2017). In this essay, we follow the traditional approach in the diversity literature to consider diversity as the distribution of differences among the members of an entity (Harrison and Klein, 2007, p. 1120). Following this rationale, we further discuss why it is essential for scholars to clearly define both their unit of analysis (i.e., the entity being studied as a whole) and 
their unit of observation (i.e., the item scholars actually observe within this entity) (Klein et al., 1994; Pfeffer, 1982).

Although Harrison and Klein (2007) focus on the individual level to understand differences among team members or within groups, their study also provides a relevant conceptual framework at levels of higher aggregation. Indeed, the logic underlying their framework is also applicable to studying differences between organizational units, such as headquarters and subsidiaries, or between alliance partners (e.g., Bertrand and Lumineau, 2016; Goerzen and Beamish, 2005). In the same way, this framework is useful for understanding diversity at the institutional level, such as differences between countries (Franke and Richey, 2010; Ostrom, 1995; Peterson et al., 2018). Whereas the IB/IM literature has focused primarily on differences at the institutional level, we suggest that it would be beneficial for scholarly inquiry to further consider differences at different levels, echoing repeated calls in the scholarly community to pay closer attention to differences at the individual and organizational levels in IB/IM research (Ambos and Håkanson, 2014; Sousa and Bradley, 2008).

Our theoretical arguments extend the previous research in IB/IM in three main ways. First, by drawing on the diversity literature, we disentangle different types of distance and their underlying mechanisms by differentiating among separation, variety, and disparity. Second, although understanding the influence of differences at the institutional level is central to IB/IM research, given its interest in cross-national distance, we emphasize that sources of diversity for many IB/IM topics originate not only at the institutional level but also at the individual or organizational level. Third, the concept of diversity is not limited to dyadic relationships (as the research on distance typically is), allowing scholars to study phenomena involving two or more entities. Therefore, our diversity lens widens the prevailing conceptualization of distance in terms of theoretical mechanisms, levels of analyses, and applicable phenomena.

\section{GOMPARING MEGHANISMS OF DISTANGE AND DIVERSITY}

The benefit of applying a diversity perspective to IB/IM research lies in the more differentiated examination of causal relationships. In contrast to the dominant distance perspective in IB/IM, a diversity perspective allows a more precise analysis of underlying theoretical mechanisms (i.e., why certain outcomes are affected), a clearer identification of relevant contexts (i.e., which outcomes are affected), and a better understanding of expected effects (i.e., whether outcomes are affected in positive or negative ways). Consequently, a diversity perspective contributes to resolving existing contradictions in the literature and laying the foundation for more accurate and rigorous empirical studies. To illuminate the potential benefits of our framework, we contrast existing theoretical arguments in the distance literature with a diversity lens to provide a more nuanced perspective on explanatory mechanisms. This approach is particularly useful, given that the literature on distance has often described different facets of distance but only implicitly distinguished their underlying mechanisms. A diversity lens can make these distinctions more palpable. 


\section{Distance as Friction: Separation}

One frequently described mechanism in the distance literature relates to information problems created by the distance between exchange partners. More specifically, scholars in IB/IM often refer to factors that inhibit the flow of information between exchange partners (see Hutzschenreuter et al., 2016). In particular, Johanson and Vahlne (1977) referred to this as psychic distance. Accordingly, distance increases the likelihood that information is transferred incompletely or incorrectly, rendering exchange more difficult and risky. Even if information is transferred completely and correctly, distant partners may still interpret the same information differently, leading to interpretation problems and misunderstandings. Given these barriers to exchange as a result of distance, Shenkar et al. (2008) advocate the term 'friction' to describe the problems associated with distance between exchange partners. Indeed, much of the literature on distance implicitly builds on the assumption that greater distance increases barriers to exchange and, thus, has a negative impact on different performance dimensions. In contrast, the diversity literature offers the construct of 'separation' to capture the analogous idea that differences in values and attitudes create barriers to exchange (Harrison and Klein, 2007). Separation is likely to result in lower cohesion, more conflicts, and lower performance because of information transfer and processing problems. Information transfer and interpretation problems caused by separation increase the barriers to exchange and are generally associated with negative outcomes. In this regard, the frequently described negative effects of cultural distance are closely related to the idea of separation. As we further explain, these effects can be analysed more precisely using the specific construct of separation rather than an imprecise reference to distance.

\section{Distance as Enrichment: Variety}

More recently, scholars have pointed to the potential upsides of distance (e.g., Stahl et al., 2016). Whereas most of the literature on distance has described the problems associated with distance, recent empirical studies have emphasized that distance can also be a source of inspiration and enrich exchange relationships (Pesch and Bouncken, 2017; Reus and Lamont, 2009). The reason is that distance allows the recombination of knowledge and expertise and the appreciation of different viewpoints. In that sense, exchanges between distant partners creates the possibility of building bridges that connect different sources of knowledge. These arguments align closely with the idea of variety in the diversity literature (Harrison and Klein, 2007). Variety denotes differences in relevant types of knowledge and experience, which facilitates creativity and improves decision quality. Thus, when scholars describe the positive effects of distance, they often implicitly refer to variety. For example, when Reus and Lamont (2009, p. 1303) emphasize the benefits of cultural distance as 'more learning opportunities' and the 'exploration of new resources and capabilities', they implicitly refer to the variety construct. However, the umbrella term of distance obscures the different natures and mechanisms of separation and variety, which has led to apparently contradictory results. Disentangling the dimensions captured by the broad term of distance provides a more nuanced perspective on these mechanisms. 


\section{Distance as Inequality: Disparity}

A third and notably less developed stream of research on distance in IB/IM has focused on inequalities (Daniels and Greguras, 2014; Winterich and Zhang, 2014). Many exchange relationships are characterized by asymmetric resource and power positions. For instance, IB/IM scholars have studied 'economic distance' using differences in GDP between countries or human development indices in various contexts (Berry et al., 2010; Dow and Karunaratna, 2006; Salomon and Wu, 2012). Relatedly, Vaara et al. (2005) argue that the choice of a common corporate language after a cross-country merger creates distance among employees and fosters the construction of superiority and inferiority. Although these studies also use the term 'distance', they refer to the effects of inequality, which differs substantially from studies that allude to the idea of friction or enrichment. In other words, the inequality stream in IB/IM addresses the hierarchical ordering of relationships along power and resource dimensions, but this discrepancy with other streams of distance research is often unclear. This idea is closely related to the notion of disparity in the diversity literature. Disparity describes differences in assets or resources and the resulting asymmetries for exchange. As such, disparity usually leads to imbalanced gains, increased internal competition, and reduced member inputs (Leung et al., 2009; Tarakci et al., 2016). Thus, the notion of disparity highlights an aspect that has suffered from an insufficient theoretical foundation in the distance literature.

\section{Distance as Diversity: A Synthesis}

The term distance has been used to denote very different things in the IB/IM literature. This is problematic because scholars appear to study identical problems; however, in reality, they differ markedly in the assumptions made and the mechanisms examined. This difference has led to a convoluted term that lacks conceptual clarity and precise underlying mechanisms. Indeed, we believe that the apparently diverging effects of distance are primarily attributable to conceptual ambiguities. In what follows, we argue that the distinction among separation, variety, and disparity provides an informative framework for IB/IM scholars interested in disentangling the term distance. As such, our work builds on an effort of typological theorizing (Doty and Glick, 1994; Reiche et al., 2019). We discuss theoretically meaningful categories to provide a parsimonious framework for understanding distance. Specifically, this approach unmasks complexities previously blurred by the use of a single concept when describing diverging realities.

\section{ADVANGING A DIVERSITY FRAMEWORK IN INTERNATIONAL BUSINESS AND MANAGEMENT}

In this section, we develop a diversity framework to enrich the study of distance in IB/IM. Diversity is the feature of an entity and, as such, is a compositional construct (Harrison and Klein, 2007). Whereas many diversity scholars have focused on a group (typically a team or a family but also a dyad as a minimal group) as their unit of analysis and on the individual member of this group as their unit of observation, we discuss different units of analysis and units of observation applied to IB/IM issues. A key advantage of 
our framework is to consider alternative units of analysis and units of observation. For example, our analytical framework invites scholars to focus on a specific country as a unit of analysis per se (e.g., Switzerland) and, as a function of scholars' particular research interests, to specify relevant entities (e.g., the different Swiss firms as members of this country) as units of observation.

In particular, we discuss the meanings of separation, variety, and disparity at the institutional, organizational, and individual levels, yielding nine distinct combinations. For each of these nine combinations, we provide an overview of the research (in IB/IM and beyond) with a few illustrative references. More importantly, we highlight potential avenues for future research on topics that are central to IB/IM research. This approach further illuminates the benefits and liabilities of each type of diversity. We suggest some theories to provide guidance and facilitate researchers' work in the pursuit of these research directions. Table I provides further explanations and research opportunities generated by the application of our framework.

On the one hand, our typology helps show the extent to which situations previously considered similar now differ by dissecting and teasing out theoretically distinct constructs and mechanisms. On the other hand, our objective is to illustrate research opportunities derived from our framework and provide some research directions by applying the framework that we propose (i.e., the use of different diversity types at the three levels). For each cell, we believe that our main contribution is to provide research avenues. In particular, we combine previously unconnected theoretical lenses by expounding on how well-established theories (e.g., social identity theory and the similarity-attraction paradigm) relate to and can be integrated into distance research in IB/IM. Hence, our theoretical contribution primarily lies in 'differentiating' and 'integrating' (MacInnis, 201 1, p. 104) theoretical perspectives and laying the ground for future empirical inquiries.

\section{Diversity at the Institutional Level}

When referring to distance, IB/IM scholars typically denote differences at the institutional level, such as regulatory and normative distance (e.g., Scott, 2013), which often relate to differences between countries. Using a diversity lens allows us to bring further nuance to the different facets of institutional distance and their potential implications for $\mathrm{IB} / \mathrm{IM}$ research.

Separation. Separation refers to differences in general attitudes, opinions, and beliefs. Separation at the institutional level has been a focal topic in IB/IM research, even if the term has not been used per se. One of the most widely applied forms of institutionallevel separation is the cultural distance between national cultures (Hofstede, 2001; Scott, 2013; Xu and Shenkar, 2002). However, the idea of institutional-level separation is not limited to cultural distance and can be composed of all forms of differences related to institutionalized normative orientations.

Importantly, but less considered in IB/IM research, institutional-level separation applies not only to the cross-national context but also to differences in professional fields or industries (Denzau and North, 1994; Pache and Santos, 2010). One example is public-private partnerships that are formed between organizations that follow distinct 


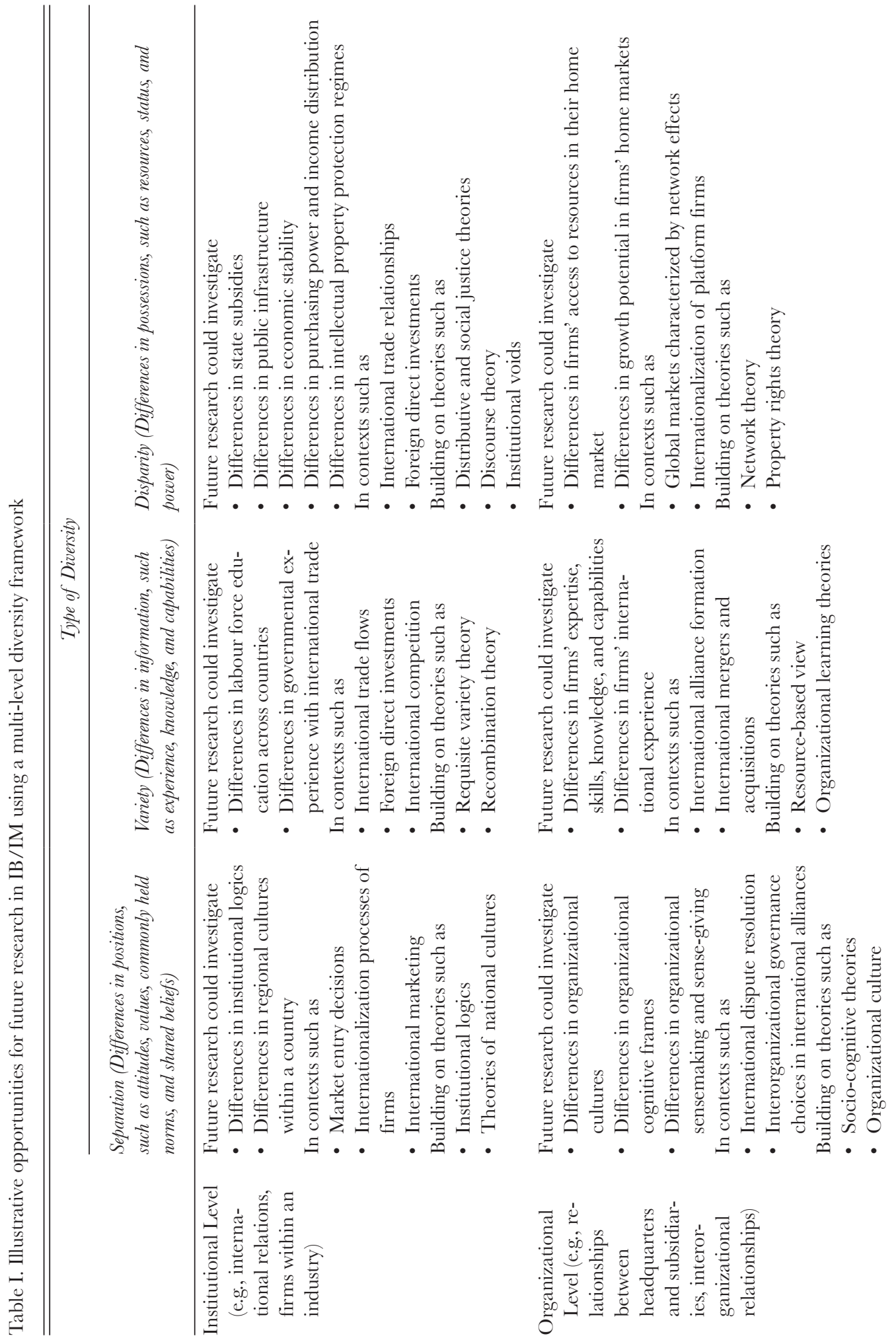




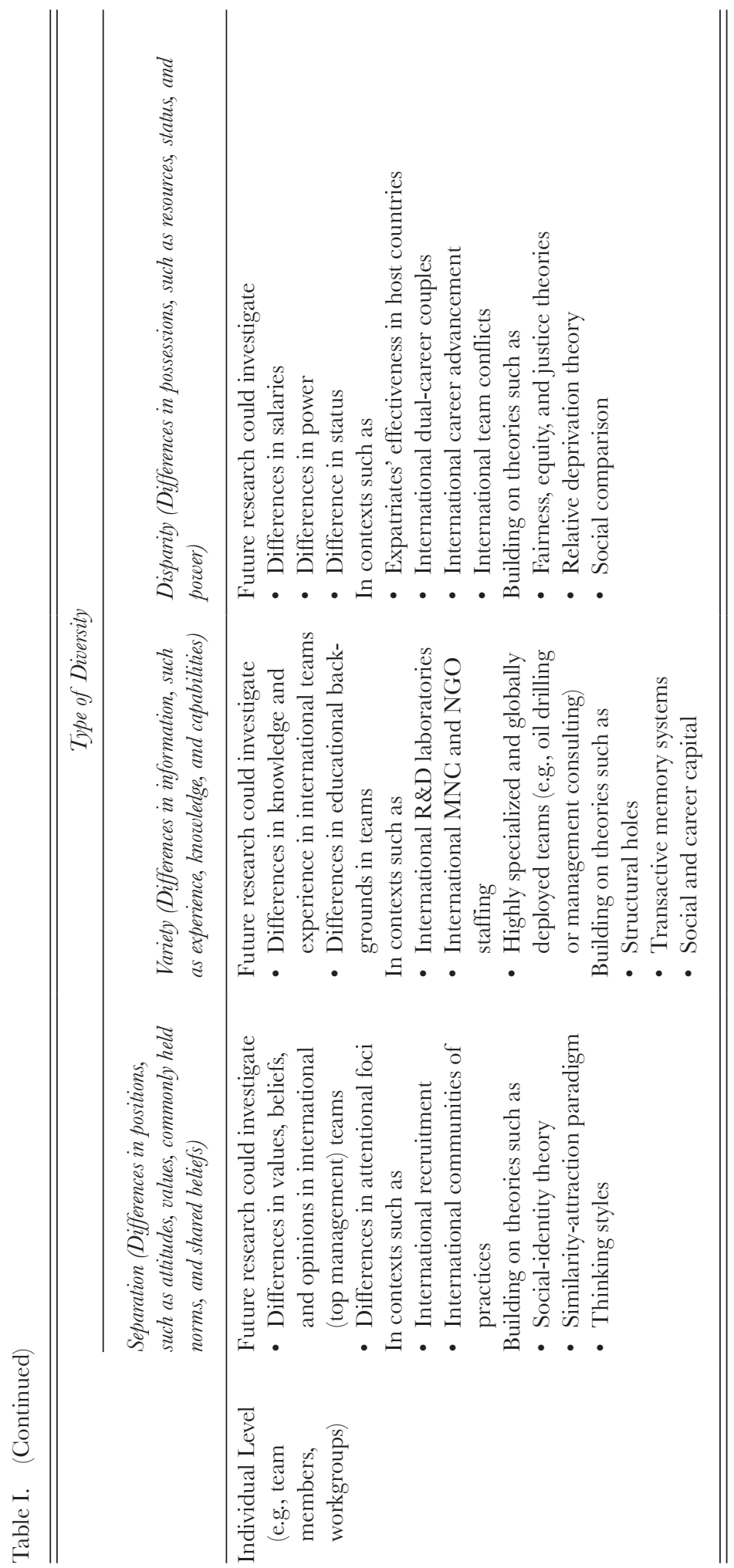


institutional logics (e.g., social welfare versus commercial exploitation; Pache and Santos, 2013). This form of separation might become relevant if a firm and a governmental institution or NGO from the same country collaborate in a foreign country - a common scenario in development projects (e.g., Dahan et al., 2010; Kolk et al., 2008). Given their different institutional logics, each party may interpret the situation, its opportunities, and its threats very differently, which may pose additional challenges to the collaboration. From a theoretical viewpoint, differences in institutional logics might explain why NGOs and firms pursue different internationalization strategies (Teegen et al., 2004). Another form of divergent logics is religious orientations that influence how people behave and make purchasing decisions (Hilary and Hui, 2009; Mathras et al., 2016). In this case, diversity describes the distribution of differences among the members of a unit with respect to religion. This form of institutional separation could be particularly relevant to international human resource management (e.g., how religious diversity in an MNC could impact HR policies) and international marketing (e.g., how religious diversity in a city could impact food consumption). More broadly, we see many opportunities for IB/ IM scholars to further analyse sources of separation at the institutional level (in addition to cultural differences across countries) as an important factor driving various IB/IMrelated issues.

Variety. Variety means differences in information, knowledge, and experience. As firms internationalize, they can (re)combine knowledge derived from multiple locations and sources in their organization, allowing them to benefit from diverse knowledge (Kogut and Zander, 1993). For instance, Balachandran and Hernandez (2018) show that firms that draw on knowledge from 'foreign' sources are more likely to realize radical innovation. In addition to the specific aspects studied so far, IB/IM studies could benefit from a more systematic exploration of institutional-level variety. One particularly applicable form of institutional variety for IB/IM relates to differences in labour training across countries. National education programs differ substantially in their foci, approaches, and priorities (e.g., hard versus soft skills), leading to variety in knowledge, skills, and experience across countries, as evidenced by comparative student evaluations (e.g., OECD, 2018). In this case, the unit of analysis could be, for instance, the European Union, and the unit of observation could be a country as a member of the European Union. These differences may be an important source of variety and influence how MNCs choose the location of new subsidiaries, hire local talent, and determine the need for expatriate staffing, which in turn may explain performance variances.

To develop their arguments, IB/IM scholars could draw on the theoretical principle of requisite variety (Ashby, 1956) to highlight the benefits of heterogeneity in information resources. Alternatively, they could draw on recombination theories that link variety to creativity and inspiration (Kaplan and Vakili, 2015). Overall, institutional-level variety represents a relatively unexplored source of differences in competitive advantages for firms operating internationally.

Disparity. Finally, institutional-level disparity refers to differences in the concentration of valued social assets or resources. This issue has been primarily situated in the domain of international economics and political science. Inequalities across countries, historical 
dependencies (e.g., colonizer versus colonized countries), imbalances in international trade flows, growth differentials, and differences in institutional strength are topics that have received considerable attention, especially in the domain of development economics (Baran, 1968; Frank, 1966). To analyse this type of disparity, the unit of analysis could be the United Nations, and the unit of observation could be a country belonging to the United Nations. Differences in access to valuable resources ranging from natural resources to political ties can explain why firms differ in their internationalization strategies (Best, 1997; Hennart, 2009; Jackson and Deeg, 2008; Meyer et al., 2009). In this context, IB/IM scholars have studied the strategic implications of institutionallevel disparities for firms operating from or in emerging economies, in which access to resources is more difficult than in developed countries (Cuervo-Cazurra and Genc, 201 1; Luo and Tung, 2007; Peng et al., 2008; Wright et al., 2005). Another source of disparity is political power, which influences the design of international trade agreements and, in turn, determines firms' ability to protect themselves against competition at home and gain access to foreign markets. More generally, institutional disparity affects both the attractiveness of a country to foreign investors and the ability of its organizations to expand abroad.

Thus, IB/IM researchers could further explore the impact of institutional-level disparities stemming from differences in public infrastructure, economic stability, disparities in income levels, and income distributions across countries. In particular, scholars could analyse disparity using distributive justice theories (e.g., Falk et al., 2008; Markovsky, 1985) and theories on power distribution in international political science (Paul et al., 2010).

\section{Diversity at the Organizational Level}

Organizational diversity encompasses differences between organizations. This idea differs from the traditional IB/IM approach in that it focuses on the differences between organizations rather than the differences in the institutional contexts in which they operate. In the following section, we discuss the potential of organizational separation, variety, and disparity as distinct sources of diversity that affect outcomes in IB/IM research.

Separation. Diversity at the organizational level has been relatively little explored, especially regarding the notion of separation, that is, differences in how organization members collectively make sense of and give meaning to situations (Gioia and Chittipeddi, 1991). Although ample literature exists to describe 'belief structures' in organizations (Kiss and Barr, 2015), including cognitive frames (Kaplan, 2008), organizational culture (Harris, 1994; Hofstede et al., 1990; Weber, 2005), and cognitive maps (Eden, 1992; LangfieldSmith, 1992), little research has explored the distance or closeness of organizations regarding normative and cognitive orientations. The exceptions are Fey and Beamish (2001) and Pothukuchi et al. (2002), who suggest that joint ventures with more similar organizational cultures show higher performance.

For IB/IM scholars, the examination of separation, such as differences in organizational cultures and cognitive frames, seems especially promising because the idea is a natural extension of studies on institutional-level cultural distance. In the context of 
international alliances and joint ventures, the similarity of organizational cultures and cognitive frames could be a major reason for partner selection, governance choices, and collaboration success (Cao et al., 2018). In particular, differences in organizational cognition remain a little-explored source of conflict and instability in international joint ventures (Habib, 1987; Lin and Germain, 1998) because partners may have very different perceptions of a situation and its possible solutions. Likewise, within MNCs, the separation between subsidiaries could inhibit coordination and knowledge transfer because of misunderstanding and distrust ( $\mathrm{Li}, 2005)$.

Variety. Aspects of organizational-level variety, such as differences in organizational knowledge and competencies, are especially relevant in the context of interorganizational relationships. A vast body of literature is devoted to the role of the complementarity of resources and information as a key driver of partnerships between different organizations (e.g., Ennen and Richter, 2010; Gulati, 1999). In this context, variety in interorganizational settings allows partners to develop new forms of collaboration, create more innovative products, and tackle more complex problems that they are unable to realize on their own (Davis, 2016; Seidl and Werle, 2018). By expanding these ideas into the realm of IB/IM research, scholars could consider how interorganizational variety allows organizations to address some of the major challenges posed in international operations, including innovating across countries and managing organizational change. For example, scholars have emphasized the potential benefits that arise when the knowledge and competencies of international subsidiaries or international alliance partners are combined (Asmussen et al., 2009; Hamel, 1991). To study this phenomenon, IB/IM scholars could draw on the resource-based view (Wernerfelt, 1984) and organizational learning theory (Fiol and Lyles, 1985; Stahl and Tung, 2015) to analyse the complementarity of resources and capabilities between organizations and the potential benefits of organizational variety.

Disparity. Disparity at the organizational level relates to differences in power and status between organizations. Organizational disparity has implications for a host of issues in the context of inter-firm collaboration. First, differences in status can influence how organizations select alliance partners. Organizations tend to favour transactions with organizations that have a similar status, especially in situations of high uncertainty and ambiguity (Chung et al., 2000; Lin et al., 2009; Podolny, 1994). Second, power disparities between partners affect how organizations make governance decisions. Aghion and Bolton (1992) argue that differences in bargaining power can distort the optimal allocation of contractual control rights, a notion that has found widespread empirical support (Adegbesan and Higgins, 2011; Kaplan and Strömberg, 2003). Third, disparity influences whether firms collaborate successfully (Lumineau and Malhotra, 2011). Indeed, status asymmetry between alliance partners seems to have a negative effect on firm performance (Lin et al., 2009; Vandaie and Zaheer, 2014). At the same time, smaller firms can improve their status and achieve higher performance by collaborating with incumbents (Stuart, 2000). In this case, disparity refers to the distribution of differences among the firms (i.e., members) of an alliance (i.e., the focal unit of analysis) with respect to status (i.e., a common attribute). 
The idea of organizational-level disparity remains relatively unexplored in IB/IM research. However, organizational disparities, such as size asymmetries between organizations and the associated power differentials, seem to be topics worth exploring in IB/IM. Large companies can leverage their size advantage when entering new markets through superior access to resources, greater market power, and economies of scale and scope to compete more ferociously against smaller local incumbents (Baum and Korn, 1999). Given the increasing importance of platforms and networks (Thomas et al., 2014), direct access to big data and customers are critical success factors for international expansion - a topic that has scarcely been touched on in IB/IM. From a theoretical perspective, IB/IM scholars could build on network theory (Shapiro and Varian, 2008) and property rights theory (Aghion and Tirole, 1994), which have described the effects of organizational size, centrality, and power differentials. Future IB/IM research could further consider the heterogeneity in firms' power and status to explain their internationalization processes.

\section{Diversity at the Individual Level}

Individual-level diversity is at the heart of the Harrison and Klein (2007) framework. Ample research has been done on the effect of individual-level diversity on team, group, and organizational performance (for reviews, see Bunderson and Van der Vegt, 2018; van Dick et al., 2008; van Knippenberg and Schippers, 2007). In the traditional IB/ IM literature, individual differences are more often aggregated and homogenized at the country level (Beugelsdijk et al., 2017), whereas a diversity approach allows for better consideration of heterogeneity at the individual level. We now turn to the implications for IB/IM and the research opportunities that emerge from a more granular understanding of diversity at the individual level in terms of separation, variety, and disparity.

Separation. The manner in which individuals perceive and interpret situations is fundamentally influenced by their deeply held attitudes, beliefs, opinions, and values (Feldman and Lynch, 1988). When individuals' attitudes, beliefs, and opinions differ; that is, when they face high separation, social interactions can become more difficult (e.g., Gibson et al., 2009; Locke and Horowitz, 1990). For example, value diversity in workgroups has been shown to negatively affect group performance and efficiency (Jehn et al., 1999). Similarly, cognitive distance, defined as differences in beliefs concerning cause-effect relationships, can increase task conflicts in teams (Olson et al., 2007), and high demographic distance deteriorates communication within and across groups (Lau and Murnighan, 2005).

For IB/IM researchers, the notion of separation may help to more accurately describe the micro-level foundations of problems related to cross-cultural teams, such as differences in the perceived separation among individuals. Indeed, few IB/IM studies have analysed differences in values, attitudes, and beliefs at the individual level, although doing so might be of great interest. For instance, several studies have highlighted the role of CEO ideologies (Chin et al., 2013), the compatibility of which could affect whether two CEOs can form strategic alliances and be successful. Our diversity lens invites us to pay further attention to the implications for IB/IM decisions of separation among 
top management team members. In particular, IB/IM scholars could use research on social identity (Tajfel, 1981; Turner, 1981), similarity attraction (Byrne, 1971; Clore, Jr. and Byrne, 1974), and social categorization (Hogg and Terry, 2000; Turner, 1985) the major theories underlying separation - to analyse the dynamics and influences of separation.

Variety. The notion of variety at the individual level denotes differences in knowledge and skills among individuals and has been explored extensively in team research. For instance, Kearney et al. (2009) show that educational diversity improves team performance. Relatedly, individual variety among employees also increases the amount and breadth of innovation (Parrotta et al., 2014). One explanation is that variety stimulates the active exchange of knowledge between group members because each member can contribute unique sources of information (Cummings, 2004).

Despite these advances, comparatively little attention has been paid to individual-level variety in the context of IB/IM research. One interesting exception is the study by Bader and Schuster (2015), which shows that variety in terms of host nationals versus foreigners within expatriates' networks increases expatriates' well-being in terrorism-engendered countries. They suggest that a variety of sources of support can better satisfy expatriates' multiple needs, simultaneously providing a large pool of tips and emotional support. More broadly, we see opportunities to leverage the influence of international team variety - in terms of experience, gender, family situation, and internationality, among many other potential factors - on expatriates' well-being, adjustment, and performance. The variety of team members' profiles may provide various types of instrumental and informational support that expatriates need, thus attenuating expatriates' feelings of loneliness, stress, and depression while helping them cope with problems and perform better. The literature on career capital (Suutari and Mäkelä, 2007), structural holes (Burt, 2004), and transactive memory systems (Ren and Argote, 2011) might provide the theoretical underpinning to describe the variety in skills and knowledge in cross-functional teams. These theories address different aspects of variety, such as social capital and knowledge differences, and might be particularly well suited for studying variety.

Disparity. Finally, individual-level disparity refers to differences in valuable assets or resources. Disparity can generate feelings of inequality, unfairness, and jealousy among individuals (Cohen-Charash and Mueller, 2007). At the same time, disparity can encourage individuals with better access to assets and resources to engage in competitive actions to secure their privileged positions (Bowers et al., 2014; Correll et al., 2017). Another consequence of disparity is that it can muffle team learning if team members with low power or status cannot adequately raise their views (Van der Vegt et al., 2010).

Although IB/IM researchers have started to investigate the consequences of individuallevel disparity, such as the effect of compensation asymmetries of expatriates relative to their local counterparts (Chen et al., 2002; Leung et al., 2009; Paik et al., 2007), they have not explored the full magnitude of individual imbalances in terms of work-related privileges, networks, and status in international settings. Our diversity lens invites us to pay further attention to disparity, particularly in the context of expatriates. Corporate expatriates (sent from headquarters to subsidiaries) typically have good access to resources 
and support from their headquarters (Au and Fukuda, 2002; Mäkelä, 2007) but may lack access to informal local networks. These disparities can manifest through distrust and jealousy in teams (Guo et al., 2017), impeding collaboration and engagement and, thus, limiting the extent to which employees share knowledge. In this context, theories on equity and justice (Adams, 1965; Rawls, 1971) and on social stratification and status might be especially useful (Bourdieu, 1977; Lenski, 1984; Saunders, 1994). These theories describe how individuals perceive and react to forms of disparity, thus providing a theoretical linkage between quantifiable disparity measures and possible social outcomes relevant to $\mathrm{IB} / \mathrm{IM}$.

\section{IMPLICATIONS OF APPLYING A DIVERSITY LENS TO DISTANGE RESEARCH}

Our diversity framework makes theoretical contributions to two important fronts in the IB/IM literature. First, we suggest that a debate exists in the IB/IM literature between the proponents of distance as a liability or as an advantage because each approach has highlighted a distinct aspect of diversity under the broader term of distance. Consequently, these two streams of research are often cited in ways that suggest contradiction. However, we are able to reconcile this apparent incompatibility through a diversity lens because the proponents of distance as a liability implicitly focus on distance as separation (e.g., Denk et al., 2012; Zaheer, 1995), whereas the proponents of distance as an advantage focus on distance as variety (e.g., Edman, 2016; Stahl et al., 2016). For instance, Edman (2016) emphasizes the potential advantages of distance by mentioning 'access to unique human capital,' 'innovation,' and 'opportunities to develop new market segments.' His arguments relate to the beneficial combination of experience and information directly associated with variety. In contrast, Pothukuchi et al. (2002) find that differences in national and organizational culture have a negative effect on international joint venture performance. In this case, the authors implicitly focus on distance as a form of separation. Thus, our diversity lens supports a more systematic and theory-grounded investigation of differences across entities.

Second, our theoretical framework extends the prevailing focus in the IB/IM literature on distance, in which the traditional unit of analysis (i.e., the entity being studied as a whole) is a pair of countries, and the traditional unit of observation (i.e., the item scholars actually observe) is a country. In contrast, a major advantage of our framework is to consider alternative units of analysis and units of observation. For example, our analytical framework also invites a focus on a specific country as a unit of analysis per se and, as a function of particular research interests, to specify relevant entities (e.g., organizations) as units of observation. In turn, scholars could study the separation, variety, and/or disparity by analysing the distribution of differences among the members of this entity with respect to a common attribute. Thus, by pointing out that diversity can originate and impact the outcomes at the institutional, organizational, and individual levels, we complement the dominant institutional-level perspective in IB/IM research. Central issues in IB/IM research, such as FDIs, MNGs, international alliances, and expatriation, may be fundamentally shaped by diversity at the individual and organizational levels rather than at the institutional level alone. 
In summary, our conceptual framework helps bridge apparent discrepancies in prior research and creates new opportunities. Through a multi-level diversity lens, scholars can develop more coherent and logical theoretical arguments on the influence of distance than is currently possible with the prevailing conceptualizations of distance in the IB/IM literature. Accordingly, our framework (1) re-joins historically disparate yet related studies, (2) reconciles apparently contradictory findings under a coherent theoretical framework, (3) broadens the conceptual range of distance research, and (4) develops an agenda for future research. In particular, further clarifying the distance construct would provide the IB/IM community with a common terminology to precisely articulate their underlying idea (Suddaby, 2010). This clarification can avoid confusion and, thus, support the accumulation of knowledge in the field. This effort to clarify the construct of distance can also foster easier operationalization (Schwab, 1980) and, in turn, a more precise empirical application of theory. In addition to facilitating communication and assisting empirical investigation, further clarity on the construct of distance can enhance creativity. Indeed, a clearly defined construct can help accurately capture the fundamental features of a phenomenon. Thus, IB/IM scholars can more easily compare similarities to and differences from related phenomena. Importantly, linking research on distance to established theories can provide a deeper theoretical foundation and allow further examination of the mechanisms underlying distance. As a result, our framework allows us to respond to the repeated calls for a more balanced consideration of the nature of distance and its distinct impacts (Dow, 2018; Zaheer et al., 2012). In particular, our framework contributes to explaining the ambivalent aspects of distance and makes conceptual distinctions that lay the foundation for a more rigorous theoretical foundation of distance research.

In addition, it is noteworthy that our diversity lens strikes a balance between richness and theoretical parsimony (Bacharach, 1989; Whetten, 1989). By breaking down the very complex and rich distance research into three well-established and nuanced constructs (i.e., separation, variety, and disparity), our framework as a whole remains practically manageable. This stands in contrast, for example, to the cultural distance construct - the most frequently studied form of distance in IB/IM - which is traditionally based on five dimensions (i.e., power distance, individualism, masculinity, uncertainty avoidance, and long-term orientation) (Hofstede, 2001). In summary, our framework provides significant additional explanatory and predictive power while remaining analytically tractable (Weick, 1989).

\section{Opportunities for Future Research}

We have discussed nine specific instances of diversity by focusing on separation, variety, and disparity at the institutional, organizational, and individual levels. Although we believe that our framework captures the most salient facets of diversity, researchers might consider additional types of diversity or levels. In some contexts, it might make sense to focus on team-level diversity. For example, the management of international joint ventures usually involves a group of individuals from each organization, each with specific interests, incentives, and preferences (Hambrick et al., 2001). In such cases, distinguishing between diversity at the individual level within each organization's team and diversity 
across teams may be relevant ( $\mathrm{Li}$ and Hambrick, 2005). Alternatively, other studies might require disentangling industry- and country-level diversity, as is often the case in international acquisitions (see Xu and Shenkar, 2002).

Another opportunity to extend our diversity framework lies in considering the types of diversity in combination. For example, different types of diversity may complement or substitute each other. Consider two engineers who can work together seamlessly because of their shared knowledge and capabilities (i.e., variety), despite their different values and attitudes (i.e., separation). In a similar vein, it might be interesting to explore how the three analytical levels discussed in our paper are interdependent and nested (Dequech, 2003). For instance, an organization member's sensemaking may be shaped by its organization's culture that, in turn, reflects industry-level orientations. Again, these orientations may be embedded in or shaped by national cultural contexts. Making direct inferences from the institutional (e.g., differences in national culture) to the individual (e.g., expatriates' behaviour) level might be seriously flawed if the nested nature of diversity (e.g., expatriates' organizational embeddedness) is ignored because distance or closeness at each level may have opposite effects (Mossholder and Bedeian, 1983).

We do not view our theoretical framework as a replacement of existing empirical research but rather as continuing and improving on prior works with an emphasis on a clearer articulation of theoretical mechanisms. Indeed, scholars can build on the solid empirical foundation and the various measures used in the IB/IM field when adopting a diversity lens. For instance, when scholars are interested in measuring country-level separation, they can take inspiration from established measures that capture different national attitudes, opinions, and beliefs (e.g., Cao et al., 2018). Similarly, disparity may be primarily related and operationalized through an assessment of economic or political differences as a function of the particular empirical setting (e.g., Franke and Richey, 2010).

In addition to the fact that our diversity framework can be embedded in existing empirical research, it also avoids certain empirical problems that current IB/IM distance research faces. As noted in recent studies (Beugelsdijk et al., 2018a; Beugelsdijk et al., 2018b), how to measure distance lacks consensus. In contrast, the diversity literature offers some concrete guidelines for measuring the constructs of separation, variety, and disparity. For example, Harrison and Klein (2007) propose the use of the standard deviation and Euclidean distance for separation, Blau's index and Teachman's entropy measure for variety, and the coefficient of variation or the Gini coefficient for disparity.

Finally, we would be amiss if we did not highlight the opportunities presented by our framework for the literature on diversity. With a few notable exceptions (e.g., Bertrand and Lumineau, 2016; Goerzen and Beamish, 2005), the diversity literature has been concerned with individual-level issues. However, this literature could be well advanced by considering diversity at the organizational and institutional levels, as proposed in our framework. Untapped opportunities exist for diversity researchers to study diversity within and across multiple levels. For instance, how would individual-level diversity unfold in alliances across different countries? Although this idea may seem complex at first sight, it is a common feature of modern work situations that bring together diverse actors. Our framework could provide an analytical structure to such complex phenomena and facilitate their explanation. 


\section{Managerial Implications}

Although the primary purpose of this paper is conceptual development, it also has significant practical implications. Most importantly, our ideas inform decision-makers about the multiple facets and levels of diversity, heightening awareness of the consequences of diversity for institutional, organizational, and individual outcomes. Understanding differences through a diversity lens has practical relevance because decision-makers can at least partially influence the level and nature of diversity in a transaction. For example, they can shape the composition of teams, choose collaboration partners, choose the markets in which firms operate, and allocate resources to divisions and subsidiaries - to name just a few relevant aspects. Whereas prior research has shown that distance and diversity have fundamental performance implications (e.g., Bae and Salomon, 2010; Roberson et al., 2017), developing a more finely grained understanding of when, how, and why distance and diversity matter is paramount from a prescriptive point of view. Our multi-level diversity lens could be particularly useful in this regard to make sense of the inherent trade-offs associated with the management of diversity. Furthermore, another practical advantage of our diversity framework is that it allows us to analyse both dyadic relationships (as has traditionally been the case with the distance construct) and relationships involving more than two parties. The latter reflects an increasing range of managerial phenomena, such as multi-cultural teams, multi-partner alliances, and networks.

\section{GONGLUSION}

Our central aim has been to develop a multi-level diversity framework to enrich the study of distance in IB/IM research. To echo the famous remark by Zaheer et al. (2012, p. 19) - 'international management is management of distance' - we advance the idea that international management is management of diversity. In particular, we demonstrate that a diversity lens can unveil distinct facets of distance and, thereby, reconcile the debate on the positive and negative aspects of distance. Moreover, we highlight that the notion of distance is not limited to institutional-level distance - the primary focus of IB/IM research - but extends to the individual and organizational levels, with relevant implications for IB/IM scholars. Thus, we intend to extend existing research on distance by offering a complementary lens that broadens the scope of research on distance. We believe that our framework can help reinvigorate this stream of research and open new perspectives on central issues in IB/IM.

\section{ACKNOWLEDGMENTS}

The authors gratefully acknowledge helpful guidance from the general editor Jonathan Doh and reviewers. In addition, João Albino-Pimentel, Olivier Bertrand, Ilya Cuypers, Adam Smale, and participants at the Academy of International Business in Copenhagen (2019) and Academy of Management in Boston (2019) provided valuable comments. 


\section{REFERENCES}

Adams, J. S. (1965). 'Inequity in social exchange'. Advances in Experimental Social Psychology, 2, 267-99.

Adegbesan, J. A. and Higgins, M. J. (201 1). 'The intra-alliance division of value created through collaboration'. Strategic Management fournal, 32, 187-211.

Aghion, P. and Bolton, P. (1992). 'An incomplete contracts approach to financial contracting'. Review of Economic Studies, 59, 473-94.

Aghion, P. and Tirole, J. (1994). 'The management of innovation'. Quarterly Fournal of Economics, 109, 1185-209.

Ambos, B. and Håkanson, L. (2014). 'The concept of distance in international management research'. Fournal of International Management, 20, 1-7.

Ashby, W. R. (1956). An Introduction to Cybernetics. London: Chapman \& Hall.

Asmussen, C. G., Pedersen, T. and Dhanaraj, C. (2009). 'Host-country environment and subsidiary competence: Extending the diamond network model'. Fournal of International Business Studies, 40, 42-57.

$\mathrm{Au}, \mathrm{K}$. Y. and Fukuda, J. (2002). 'Boundary spanning behaviors of expatriates'. Fournal of World Business, 37, 285-96.

Bacharach, S. B. (1989). 'Organizational theories: Some criteria for evaluation'. Academy of Management Reviere, 14, 496-515.

Bader, B. and Schuster, T. (2015). 'Expatriate social networks in terrorism-endangered countries: An empirical analysis in Afghanistan, India, Pakistan, and Saudi Arabia'. Fournal of International Management, 21, 63-77.

Bae, J.-H. and Salomon, R. M. (2010). 'Institutional distance in international business research'. In Tihanyi, L., Devinney, T. M. and Pedersen, T. (Eds), The Past, Present and Future of International Business \& Management. Bingley: Emerald, 23, 327-49.

Balachandran, S. and Hernandez, E. (2018). 'Networks and innovation: accounting for structural and institutional sources of recombination in brokerage triads'. Organization Science, 29, 80-99.

Baran, P. A. (1968). The Political Economy of Growth. New York: New York University Press.

Baum, J. A. C. and Korn, H. J. (1999). 'Dynamics of dyadic competitive interaction'. Strategic Management fournal, 20, 251-78.

Bell, S. T., Villado, A. J., Lukasik, M. A., Belau, L. and Briggs, A. L. (2011). 'Getting specific about demographic diversity variable and team performance relationships: A meta-analysis'. Fournal of Management, 37, 709-43.

Berry, H., Guillén, M. F. and Zhou, N. (2010). 'An institutional approach to cross-national distance'. Fournal of International Business Studies, 41, 1460-80.

Bertrand, O. and Lumineau, F. (2016). 'Partners in crime: The effects of diversity on the longevity of cartels'. Academy of Management Fournal, 59, 983-1008.

Best, A. D. (1997). International Diversity versus International Diversification: Host Country Effects on Multinational Firm Performance. College Station, TX: Texas A\&M University.

Beugelsdijk, S., Ambos, B. and Nell, P. C. (2018a). 'Conceptualizing and measuring distance in international business research: Recurring questions and best practice guidelines'. Fournal of International Business Studies, 43, 1113-37.

Beugelsdijk, S., Kostova, T., Kunst, V. E., Spadafora, E. and van Essen, M. (2018b). 'Cultural distance and firm internationalization: A meta-analytical review and theoretical implications'. Fournal of Management, 44, 89-130.

Beugelsdijk, S., Kostova, T. and Roth, K. (2017). 'An overview of hofstede-inspired country-level culture research in international business since 2006'. Fournal of International Business Studies, 48, 30-47.

Bourdieu, P. (1977). Outline of a Theory of Practice. Cambridge: Cambridge University Press.

Bowers, A. H., Greve, H. R., Mitsuhashi, H. and Baum, J. A. C. (2014). 'Competitive parity, status disparity, and mutual forbearance: Securities analysts' competition for investor attention'. Academy of Management Journal, 57, 38-62.

Bunderson, J. S. and Sutcliffe, K. M. (2002). 'Comparing alternative conceptualizations of functional diversity in management teams: Process and performance effects'. Academy of Management Fournal, 45, 875-93.

Bunderson, J. S. and Van der Vegt, G. S. (2018). 'Diversity and inequality in management teams: A review and integration of research on vertical and horizontal member differences'. Annual Review of Organizational Psychology and Organizational Behavior, 5, 47-73.

Burt, R. S. (2004). 'Structural holes and good ideas'. American fournal of Sociology, 110, 349-99.

Byrne, D. E. (1971). The Attraction Paradigm. New York: Academic Press. 
Cao, Z., Li, Y., Jayaram, J., Liu, Y. and Lumineau, F. (2018). 'A meta-analysis of the exchange hazardsinterfirm governance relationship: An informal institutions perspective'. Fournal of International Business Studies, 49, 303-23.

Chen, C. C., Choi, J. and Chi, S. (2002). 'Making justice sense of local-expatriate compensation disparity: Mitigation by local referents, ideological explanations, and interpersonal sensitivity in China-foreign joint ventures'. Academy of Management fournal, 45, 807-17.

Chin, M. K., Hambrick, D. G. and Treviño, L. K. (2013). 'Political ideologies of CEOs: The influence of executives' values on corporate social responsibility'. Administrative Science Quarterly, 58, 197-232.

Chung, S. A., Singh, H. and Lee, K. (2000). 'Complementarity, status similarity and social capital as drivers of alliance formation'. Strategic Management fournal, 21, 1-22.

Clore, G. L. Jr. and Byrne, D. E. (1974). 'A reinforcement model of attraction: A multilevel conceptualization of theory-construction and theory-testings'. In Huston, T. L. (Ed.), Perspective on Interpersonal Attraction. New York: Academic Press, 143-70.

Cohen-Charash, Y. and Mueller, J. S. (2007). 'Does perceived unfairness exacerbate or mitigate interpersonal counterproductive work behaviors related to envy?' Gournal of Applied Psychology, 92, 666-80.

Correll, S. J., Ridgeway, C. L., Zuckerman, E. W., Jank, S., Jordan-Bloch, S. and Nakagawa, S. (2017). 'It's the conventional thought that counts: How third-order inference produces status advantage'. American Sociological Reviewe, 82, 297-327.

Cuervo-Cazurra, A. and Genc, M. E. (2011). 'Obligating, pressuring, and supporting dimensions of the environment and the non-market advantages of developing-country multinational companies'. Fournal of Management Studies, $\mathbf{4 8}, 441-55$.

Cummings, J. N. (2004). 'Work groups, structural diversity, and knowledge sharing in a global organization'. Management Science, 50, 352-64.

Dahan, N. M., Doh, J. P., Oetzel, J. and Yaziji, M. (2010). 'Corporate-NGO collaboration: Co-creating new business models for developing markets'. Long Range Planning, 43, 326-42.

Daniels, M. A. and Greguras, G. J. (2014). 'Exploring the nature of power distance: Implications for microand macro-level theories, processes, and outcomes'. Fournal of Management, 40, 1202-29.

Davis, J. P. (2016). 'The group dynamics of interorganizational relationships'. Administrative Science Quarterly, 61, 621-61.

Denk, N., Kaufmann, L. and Roesch, J.-F. (2012) . 'Liabilities of foreignness revisited: A review of contemporary studies and recommendations for future research'. Fournal of International Management, 18, 322-34.

Denzau, A. T. and North, D. C. (1994). 'Shared mental models: Ideologies and institutions'. Kyklos, 47, 3-31.

Dequech, D. (2003). 'Cognitive and cultural embeddedness: Combining institutional economics and economic sociology'. Fournal of Economic Issues, 37, 461-70.

Dikova, D. and Rao Sahib, P. (2013). 'Is cultural distance a bane or a boon for cross-border acquisition performance?'. Fournal of World Business, 48, 77-86.

Doty, D. H. and Glick, W. H. (1994). 'Typologies as a unique form of theory building: Toward improved understanding and modeling'. Academy of Management Review, 19, 230-51.

Dow, D. (2018). 'Are we at a turning point for distance research in international business studies?'. In Verbeke, A., Puck, J. and van Tulder, R. (Eds), Distance in International Business: Concept, Cost and Value. Bingley: Emerald Publishing, 47-68.

Dow, D. and Karunaratna, A. (2006). 'Developing a multidimensional instrument to measure psychic distance stimuli'. Fournal of International Business Studies, 37, 578-602.

Eden, C. (1992). 'On the nature of cognitive maps'. Fournal of Management Studies, 29, 261-65.

Edman, J. (2016). 'Reconciling the advantages and liabilities of foreignness: Towards an identity-based framework'. Fournal of International Business Studies, 47, 674-94.

Ennen, E. and Richter, A. (2010). 'The whole is more than the sum of its parts - or is it? A review of the empirical literature on complementarities in organizations'. Fournal of Management, 36, 207-33.

Falk, A., Fehr, E. and Fischbacher, U. (2008). 'Testing theories of fairness - intentions matter'. Games and Economic Behavior, 62, 287-303.

Feldman, J. M. and Lynch, J. G. (1988). 'Self-generated validity and other effects of measurement on belief, attitude, intention, and behavior'. Fournal of Applied Psychology, 73, 421-35.

Fey, C. F. and Beamish, P. W. (2001). 'Organizational climate similarity and performance: International joint ventures in Russia'. Organization Studies, 22, 853-82.

Fiol, C. M. and Lyles, M. A. (1985). 'Organizational learning'. Academy of Management Review, 10, 803-13.

Frank, A. G. (1966). 'The development of underdevelopment'. Monthly Review, 18, 17-31.

Franke, G. R. and Richey, R. G. (2010). 'Improving generalizations from multi-country comparisons in international business research'. Fournal of International Business Studies, 41, 1275-93. 
Gibson, C. B., Cooper, C. D. and Conger, J. A. (2009). 'Do you see what we see? The complex effects of perceptual distance between leaders and teams'. Fournal of Applied Psychology, 94, 62-76.

Gioia, D. A. and Chittipeddi, K. (1991). 'Sensemaking and sensegiving in strategic change initiation'. Strategic Management Fournal, 12, 433-48.

Goerzen, A. and Beamish, P. W. (2005). 'The effect of alliance network diversity on multinational enterprise performance'. Strategic Management Fournal, 26, 333-54.

Gulati, R. (1999). 'Network location and learning: The influence of network resources and firm capabilities on alliance formation'. Strategic Management fournal, 20, 397-420.

Guo, S.-L., Lumineau, F. and Lewicki, R. J. (2017). 'Revisiting the foundations of organizational distrust'. Foundations and Trends in Strategic Management, 1, 1-88.

Habib, G. M. (1987). 'Measures of manifest conflict in international joint ventures'. Academy of Management fournal, 30, 808-16.

Håkanson, L. and Ambos, B. (2010). 'The antecedents of psychic distance'. Fournal of International Management, 16, 195-210.

Hambrick, D. C., Li, J., Xin, K. R. and Tsui, A. S. (2001). 'Compositional gaps and downward spirals in international joint venture management groups'. Strategic Management fournal, 22, 1033-53.

Hamel, G. (1991). 'Competition for competence and interpartner learning within international strategic alliances'. Strategic Management fournal, 12, 83-103.

Harris, S. G. (1994). 'Organizational culture and individual sensemaking: A schema-based perspective'. Organization Science, 5, 309-21.

Harrison, D. A. and Klein, K. J. (2007). 'What's the difference? Diversity constructs as separation, variety, or disparity in organizations'. Academy of Management Review, 32, 1199-228.

Hennart, J.-F. (2009). 'Down with MNE-centric theories! market entry and expansion as the bundling of MNE and local assets'. Fournal of International Business Studies, 40, 1432-54.

Hilary, G. and Hui, K. W. (2009). 'Does religion matter in corporate decision making in America?'. Fournal of Financial Economics, 93, 455-73.

Hofstede, G. (2001). Culture's Consequences: Comparing Values, Behaviors, Institutions, and Organizations across Nations, 2nd edition. Thousand Oaks, CA: SAGE Publications.

Hofstede, G., Neuijen, B., Ohayv, D. D. and Sanders, G. (1990). 'Measuring organizational cultures: A qualitative and quantitative study across twenty cases'. Administrative Science Quarterly, 35, 286-316.

Hogg, M. A. and Terry, D. J. (2000). 'Social identity and self-categorization processes in organizational contexts'. Academy of Management Review, 25, 121-40.

Hutzschenreuter, T., Kleindienst, I. and Lange, S. (2016). 'The concept of distance in international business research: A review and research agenda'. International fournal of Management Revieres, 18, 160-79.

Jackson, G. and Deeg, R. (2008). 'Comparing capitalisms: Understanding institutional diversity and its implications for international business'. Fournal of International Business Studies, 39, 540-61.

Jehn, K. A., Northcraft, G. B. and Neale, M. A. (1999). 'Why differences make a difference: A field study of diversity, conflict, and performance in workgroups'. Administrative Science Quarterly, 44, 741-63.

Joardar, A. and Wu, S. (2017). 'Liabilities and benefits: Examining the two sides of the foreignness coin from entrepreneurial perspective'. International Business Review, 26, 1157-67.

Johanson, J. and Vahlne, J.-E. (1977). 'The internationalization process of the firm - a model of knowledge development and increasing foreign market commitments'. Fournal of International Business Studies, 8, 23-32.

Johanson, J. and Vahlne, J.-E. (2009). 'The Uppsala internationalization process model revisited: From liability of foreignness to liability of outsidership'. Fournal of International Business Studies, 40, 1411-31.

Kaplan, S. (2008). 'Framing contests: Strategy making under uncertainty'. Organization Science, 19, 729-52.

Kaplan, S. N. and Strömberg, P. (2003). 'Financial contracting theory meets the real world: An empirical analysis of venture capital contracts'. Review of Economic Studies, 70, 281-315.

Kaplan, S. and Vakili, K. (2015). 'The double-edged sword of recombination in breakthrough innovation'. Strategic Management fournal, 36, 1435-57.

Kearney, E., Gebert, D. and Voelpel, S. C. (2009). 'When and how diversity benefits teams: The importance of team members' need for cognition'. Academy of Management fournal, 52, 581-98.

Kirkman, B. L., Lowe, K. B. and Gibson, C. B. (2006). 'A quarter century of culture's consequences: A review of empirical research incorporating Hofstede's cultural values framework'. Fournal of International Business Studies, 37, 285-320.

Kirkman, B. L., Lowe, K. B. and Gibson, C. B. (2017). 'A retrospective on culture's consequences: The 35year journey'. Fournal of International Business Studies, 48, 12-29.

Kiss, A. N. and Barr, P. S. (2015). 'New venture strategic adaptation: The interplay of belief structures and industry context'. Strategic Management Fournal, 36, 1245-63. 
Klein, K. J., Dansereau, F. and Hall, R. J. (1994). 'Levels issues in theory development, data collection, and analysis'. Academy of Management Review, 19, 195-229.

Kogut, B. and Singh, H. (1988). 'The effect of national culture on the choice of entry mode'. Fournal of International Business Studies, 19, 411-32.

Kogut, B. and Zander, U. (1993). 'Knowledge of the firm and the evolutionary theory of the multinational corporation'. Journal of International Business Studies, 24, 625-45.

Kolk, A., van Tulder, R. and Kostwinder, E. (2008). 'Business and partnerships for development'. European Management fournal, 26, 262-73.

Langfield-Smith, K. (1992). 'Exploring the need for a shared cognitive map'. Fournal of Management Studies, 29, 349-68.

Lau, D. C. and Murnighan, J. K. (2005). 'Interactions within groups and subgroups: The effects of demographic faultines'. Academy of Management fournal, 48, 645-59.

Lenski, G. (1984). Power and Privilege: A Theory of Social Stratification. Chapel Hill, NC: University of North Carolina Press.

Leung, K., Zhu, Y. and Ge, C. (2009). 'Compensation disparity between locals and expatriates: Moderating the effects of perceived injustice in foreign multinationals in China'. Fournal of World Business, 44, 85-93.

Li, J. and Hambrick, D. C. (2005). 'Factional groups: A new vantage on demographic faultlines, conflict, and disintegration in work teams'. Academy of Management fournal, 48, 794-813.

Li, L. (2005). 'The effects of trust and shared vision on inward knowledge transfer in subsidiaries' intra- and inter-organizational relationships'. International Business Review, 14, 77-95.

Lin, X. and Germain, R. (1998). 'Sustaining satisfactory joint venture relationships: The role of conflict resolution strategy'. Journal of International Business Studies, 29, 179-96.

Lin, Z., Yang, H. and Arya, B. (2009). 'Alliance partners and firm performance: Resource complementarity and status association'. Strategic Management fournal, 30, 921-40.

Locke, K. D. and Horowitz, L. M. (1990). 'Satisfaction in interpersonal interactions as a function of similarity in level of dysphoria'. Fournal of Personality and Social Psychology, 58, 823-31.

Lumineau, F. and Malhotra, D. (2011). 'Shadow of the contract: How contract structure shapes interfirm dispute resolution'. Strategic Management fournal, 32, 532-55.

Luo, Y. and Tung, R. L. (2007). 'International expansion of emerging market enterprises: A springboard perspective'. Fournal of International Business Studies, 38, 481-98.

MacInnis, D. J. (2011). 'A framework for conceptual contributions in marketing'. Fournal of Marketing, 75, $136-54$.

Mäkelä, K. (2007). 'Knowledge sharing through expatriate relationships: A social capital perspective'. International Studies of Management Ë Organization, 37, 108-25.

Markovsky, B. (1985). 'Toward a multilevel distributive justice theory'. American Sociological Review, 50, $822-39$.

Maseland, R., Dow, D. and Steel, P. (2018). 'The Kogut and Singh national cultural distance index: Time to start using it as a springboard rather than a crutch'. Fournal of International Business Studies, 49, 1154-66.

Mathras, D., Cohen, A. B., Mandel, N. and Mick, D. G. (2016). 'The effects of religion on consumer behavior: A conceptual framework and research agenda'. Fournal of Consumer Psychology, 26, 298-311.

Meyer, K. E., Estrin, S., Bhaumik, S. K. and Peng, M. W. (2009). 'Institutions, resources, and entry strategies in emerging economies'. Strategic Management fournal, 30, 61-80.

Mossholder, K. W. and Bedeian, A. G. (1983). 'Cross-level inference and organizational research: Perspectives on interpretation and application'. Academy of Management Review, 8, 547-58.

Nishii, L. H., Khattab, J., Shemla, M. and Paluch, R. M. (2018). 'A multi-level process model for understanding diversity practice effectiveness'. Academy of Management Annals, 12, 37-82.

OECD (2018). PISA 2018 Results. Paris: OECD Publishing.

Olson, B. J., Parayitam, S. and Bao, Y. (2007). 'Strategic decision making: The effects of cognitive diversity, conflict, and trust on decision outcomes'. Journal of Management, 33, 196-222.

Ostrom, E. (1995). Understanding Institutional Diversity. Princeton, NJ: Princeton University Press.

Oxford University Press (2020). Oxford Learner's Dictionary of Academic English. Available at: https://www.oxfor dlearnersdictionaries.com/definition/academic/distancel (accessed 10 December 2020).

Pache, A.-C. and Santos, F. (2010). 'When worlds collide: The internal dynamics of organizational responses to conflicting institutional demands'. Academy of Management Review, 35, 455-76.

Pache, A.-C. and Santos, F. (2013). 'Inside the hybrid organization: Selective coupling as a response to competing institutional logics'. Academy of Management fournal, 56, 972-1001.

Paik, Y., Parboteeah, K. P. and Shim, W. (2007). 'The relationship between perceived compensation, organizational commitment and job satisfaction: The case of Mexican workers in the Korean Maquiladoras'. International fournal of Human Resource Management, 18, 1768-81. 
Parrotta, P., Pozzoli, D. and Pytlikova, M. (2014). 'The Nexus between labor diversity and firm's innovation'. Fournal of Population Economics, 27, 303-64.

Paul, T. V., Wirtz, J. J. and Fortmann, M. (Eds) (2010). Balance of Power: Theory and Practice in the 21st Century. Stanford, CA: Stanford University Press.

Peng, M. W., Wang, D. Y. L. and Jiang, Y. (2008). 'An institution-based view of international business strategy: A focus on emerging economies'. Fournal of International Business Studies, 39, 920-36.

Pesch, R. and Bouncken, R. B. (2017). 'The double-edged sword of cultural distance in international alliances'. Cross Cultural \& Strategic Management, 24, 33-54.

Peterson, M. F., Søndergaard, M. and Kara, A. (2018). 'Traversing cultural boundaries in IB: The complex relationships between explicit country and implicit cultural group boundaries at multiple levels'. Fournal of International Business Studies, 49, 1081-99.

Pfeffer, J. (1982). Organizations and Organization Theory. Boston, MA: Pitman.

Podolny, J. M. (1994). 'Market uncertainty and the social character of economic exchange'. Administrative Science Quarterly, 39, 458-83.

Pothukuchi, V., Damanpour, F., Choi, J., Chen, C. C. and Park, S. H. (2002). 'National and organizational culture differences and international joint venture performance'. Fournal of International Business Studies, 33, 243-65.

Rawls, J. (1971). A Theory of Justice. Cambridge, MA: Harvard University Press.

Reiche, B. S., Lee, Y. and Allen, D. G. (2019). 'Actors, structure, and processes: A review and conceptualization of global work integrating IB and HRM research'. Fournal of Management, 45, 359-83.

Ren, Y. and Argote, L. (2011). 'Transactive memory systems 1985-2010: An integrative framework of key dimensions, antecedents, and consequences'. Academy of Management Annals, 5, 189-229.

Reus, T. H. and Lamont, B. T. (2009). 'The double-edged sword of cultural distance in international acquisitions'. Fournal of International Business Studies, 40, 1298-316.

Roberson, Q., Holmes, O. and Perry, J. L. (2017). 'Transforming research on diversity and firm performance: A dynamic capabilities perspective'. Academy of Management Annals, 11, 189-216.

Salomon, R. M. and Wu, Z. (2012). 'Institutional distance and local isomorphism strategy'. Fournal of International Business Studies, 43, 343-67.

Saunders, P. (1994). Social Class and Stratification. London: Routledge.

Schwab, D. P. (1980). 'Construct validity in organizational behavior'. In Cummings, L. L. and Staw, B. M. (Eds), Research in Organizational Behavior: An Annual Series of Analytical Essays and Critical Reviewes. Greenwich, CT: JAI Press, 3-43.

Scott, W. R. (2013). Institutions and Organizations: Ideas, Interests, and Identities, 4th edition. Los Angeles, CA: SAGE Publications.

Seidl, D. and Werle, F. (2018). 'Inter-organizational sensemaking in the face of strategic meta-problems: Requisite variety and dynamics of participation'. Strategic Management fournal, 39, 830-58.

Shapiro, C. and Varian, H. R. (2008). Information Rules: A Strategic Guide to the Network Economy. Boston, MA: Harvard Business School Press.

Shenkar, O. (2001). 'Cultural distance revisited: Towards a more rigorous conceptualization and measurement of cultural differences'. Fournal of International Business Studies, 32, 519-35.

Shenkar, O. (2012). 'Beyond cultural distance: Switching to a friction lens in the study of cultural differences'. Fournal of International Business Studies, 43, 12-7.

Shenkar, O., Luo, Y. and Yeheskel, O. (2008). "From "distance" to "friction": Substituting metaphors and redirecting intercultural research'. Academy of Management Reviewe, 33, 905-23.

Sousa, C. M. P. and Bradley, F. (2008). 'Cultural distance and psychic distance: Refinements in conceptualisation and measurement'. Fournal of Marketing Management, 24, 467-88.

Srikanth, K., Harvey, S. and Peterson, R. (2016). 'A dynamic perspective on diverse teams: Moving from the dual-process model to a dynamic coordination-based model of diverse team performance'. Academy of Management Annals, 10, 453-93.

Stahl, G. K., Miska, C., Lee, H.-J. and de Luque, M. S. (2017). 'The upside of cultural differences: Towards a more balanced treatment of culture in cross-cultural management research'. Cross Cultural EO Strategic Management, 24, 2-12.

Stahl, G. K. and Tung, R. L. (2015). 'Towards a more balanced treatment of culture in international business studies: The need for positive cross-cultural scholarship'. Fournal of International Business Studies, $\mathbf{4 6}$, 391-414.

Stahl, G. K., Tung, R. L., Kostova, T. and Zellmer-Bruhn, M. E. (2016). 'Widening the lens: Rethinking distance, diversity, and foreignness in international business research through positive organizational scholarship'. Fournal of International Business Studies, 47, 621-30. 
Stuart, T. E. (2000). 'Interorganizational alliances and the performance of firms: A study of growth and innovation rates in a high-technology industry'. Strategic Management fournal, 21, 791-81 1.

Suddaby, R. (2010). 'Editor's comments: Construct clarity in theories of management and organization'. Academy of Management Review, 35, 346-57.

Suutari, V. and Mäkelä, K. (2007). 'The career capital of managers with global careers'. Fournal of Managerial Psychology, 22, 628-48.

Tajfel, H. (1981). Human Groups and Social Categories: Studies in Social Psychology. Cambridge, MA: Cambridge University Press.

Tarakci, M., Greer, L. L. and Groenen, P. J. F. (2016). 'When does power disparity help or hurt group performance?'. Fournal of Applied Psychology, 101, 415-29.

Teegen, H., Doh, J. P. and Vachani, S. (2004). 'The importance of nongovernmental organizations (NGOs) in global governance and value creation: An international business research agenda'. Fournal of International Business Studies, 35, 463-83.

Thomas, L. D. W., Autio, E. and Gann, D. M. (2014). 'Architectural leverage: Putting platforms in context'. Academy of Management Perspectives, 28, 198-219.

Tihanyi, L., Griffith, D. A. and Russell, C. J. (2005). 'The effect of cultural distance on entry mode choice, international diversification, and MNE performance: A meta-analysis'. Fournal of International Business Studies, 36, 270-83.

Tung, R. L. and Verbeke, A. (2010). 'Beyond Hofstede and GLOBE: Improving the quality of cross-cultural research'. Journal of International Business Studies, 41, 1259-74.

Turner, J. C. (1981). 'Towards a cognitive redefinition of the social group'. In Tajfel, H. (Ed.), Social Identity and Intergroup Relations. Cambridge: Cambridge University Press, 15-40.

Turner, J. C. (1985). 'Social categorization and the self-concept: A social cognitive theory of group behavior'. In Lawler, E. J. (Ed.), Advances in Group Processes: Theory and Research. Greenwich, CT: JAI Press, 2, 77-122.

Vaara, E., Tienari, J., Piekkari, R. and Säntti, R. (2005). 'Language and the circuits of power in a merging multinational corporation'. Fournal of Management Studies, 42, 595-623.

Van der Vegt, G. S., de Jong, S. B., Bunderson, J. S. and Molleman, E. (2010). 'Power asymmetry and learning in teams: The moderating role of performance feedback'. Organization Science, 21, 347-61.

van Dick, R., van Knippenberg, D., Hägele, S., Guillaume, Y. R. and Brodbeck, F. C. (2008). 'Group diversity and group identification: The moderating role of diversity beliefs'. Human Relations, 61, 1463-92.

van Dijk, H., Meyer, B., van Engen, M. and Loyd, D. L. (2017). 'Microdynamics in diverse teams: A review and integration of the diversity and stereotyping literatures'. Academy of Management Annals, 11, 517-57.

van Knippenberg, D., de Dreu, C. K. W. and Homan, A. C. (2004). 'Work group diversity and group performance: An integrative model and research agenda'. Fournal of Applied Psychology, 89, 1008-22.

van Knippenberg, D. and Schippers, M. C. (2007). 'Work group diversity'. Annual Review of Psychology, 58, 515-41.

Vandaie, R. and Zaheer, A. (2014). 'Surviving bear hugs: Firm capability, large partner alliances, and growth'. Strategic Management fournal, 35, 566-77.

Verbeke, A., Puck, J. and van Tulder, R. (Eds) (2018a). Distance in International Business: Concept, Cost and Value. Bingley: Emerald Publishing.

Verbeke, A., van Tulder, R. and Puck, J. (2018b). 'Distance in international business studies: Concept, cost and value'. In Verbeke, A., Puck, J. and van Tulder, R. (Eds), Distance in International Business: Concept, Cost and Value. Bingley: Emerald Publishing, 17-43.

Weber, K. (2005). 'A toolkit for analyzing corporate cultural toolkits'. Poetics, 33, 227-52.

Weick, K. E. (1989). 'Theory construction as disciplined imagination'. Academy of Management Review, 14, 516-31.

Wernerfelt, B. (1984). 'A resource-based view of the firm'. Strategic Management fournal, 5, 171-80.

Whetten, D. A. (1989). 'What constitutes a theoretical contribution?' Academy of Management Review, 14, 490-5.

Winterich, K. P. and Zhang, Y. (2014). 'Accepting inequality deters responsibility: How power distance decreases charitable behavior'. Journal of Consumer Research, 41, 274-93.

Wright, M., Filatotchev, I., Hoskisson, R. E. and Peng, M. W. (2005). 'Strategy research in emerging economies: Challenging the conventional wisdom'. Fournal of Management Studies, 42, 1-33.

$\mathrm{Xu}$, D. and Shenkar, O. (2002). 'Note: Institutional distance and the multinational enterprise'. Academy of Management Review, 27, 608-18.

Zaheer, S. (1995). 'Overcoming the liability of foreignness'. Academy of Management fournal, 38, 341-63.

Zaheer, S., Schomaker, M. S. and Nachum, L. (2012). 'Distance without direction: Restoring credibility to a much-loved construct'. Fournal of International Business Studies, 43, 18-27. 